\title{
ETHICAL RESEARCH DILEMMAS AND THEIR IMPLICATIONS IN ENGLISH LANGUAGE TEACHING STUDIES
}

\author{
Daniel Ginting 1 , \\ 1, Universitas Ma Chung \\ Email: daniel.ginting@ machung.ac.id.
}

\begin{abstract}
Researchers across the disciplines, including those whose passions are in English teaching studies, are always challenged to continuously contribute their research findings to the development of science. However, ethical considerations must be adhered to when they involve humans as participants in their study. Ethical dilemmas, even though they are considered important, are still rarely discussed. Thus, depicting the sketch of a comprehensive configuration of ethical dimensions is extremely needed for ESL researchers to serve as a guidance to carry out their research. This paper concludes with some ethical implications for researchers to carry out research ethically.
\end{abstract}

Keywords: Ethical, research, English Language Teaching, informed consent.

\section{(i)}

This work is licensed under Creative Commons Attribution License 4.0 CC-BY International license

\section{INTRODUCTION}

Conduction research ethically is a must for all researchers to do, regardless of their field of study. Nevertheless, our history has recorded that carrying out research ethically is not always easy to do. The Tuskegee study on syphilis effects, for example, is an example of a well-known and world-shaking study where ethical considerations have hardly been adhered to (Shavers et al., 2000; White, 2000; Alsan et al., 2020).

Violations of ethical norms in research eventually prompted the international movement to formulate standards about ethical considerations in research. As a result, this movement resulted in the Nuremberg Code (Shuster, 1997), which later prompted the National Commission for the Protection of Human Subjects of Biomedical and Behavioral Research to formulate the Belmont Report in 1978 (Sims, 2010; Friesen et al., 2017). Based on this Belmont Report, three principles become the basis for ethical considerations for researchers when involving humans as the subject of study: beneficence, respect, and justice (Merrell \& Williams, 1995; Cassell, 2000). Beneficence means maximizing good results while minimizing risk or maximizing possible benefits and minimizing possible harms. Respect requires researchers to respect research participants by protecting their autonomy, ensuring the study's voluntary nature, and delivering well-informed participation of research subjects in research. Respect relates to dignity, freedom 
to make their own decisions. Justice offers equal opportunity for research subjects to benefit from research results.

Nowadays, colleges in America have established IRBs (Institutional Review Board), consisting of local internal and external stakeholders, to monitor compliance researchers on ethical issues in research. Several well-known professional associations whose duty is to monitor ethical actions in research include the American Educational Research Association (Strike, et al., 2002), Ethical Principles of Psychologists and Code of Conduct (APA, 2016), the American Anthropological Association/AAA (Dreger, 2011), and the Joint Committee on Standards for Educational Evaluation (Stufflebeam, 2004).

Ethical dilemmas in research in English language teaching (ELT) is also a crucial topic; however, this topic has been understudied. Eaton (2020), for example, emphasized that ethical issues in teaching English are inevitable. Unfortunately, the regulatory and guiding statements for researchers are still unclear. By examining research issues-related documents from several developed countries, she found four key aspects of research related to language teaching: informed consent, translation and interpretation, the use of intermediaries and knowledge mobilization and dissemination. of findings. Moreover, Cephe and Keles (2015) researched the extent to which English teachers have implemented the ethical code towards students during their teaching process. They found that the students and teachers had different perceptions about the application of those ethical principles, including discipline according to law and school policy. Gu and Lai (2019) investigates secondary school English (ESL) teachers regulated their teaching and practices and constructed their identities in relation to governmental requirements for the use of IT in teaching. They found that there was an identity dilemma for teachers. While they are trying to achieve the expectations of the government to be skilled with IT. However, they, on the other hand, still have to struggle with the expectations of the government. This condition is what researchers call the term 'governmentality. From this research, the contradiction is described by several terms such as professional/personal demands, compliance/resistance, and so on.

From this systematic literature review, the author finds the dynamics of progressive research results in the fields of science, explainig phenomena and ethical dilemmas in which humans are used as participants in research. For that reason, the author presents several cases in those fields of studies as the examples. Meanwhile, ethical dilemmas, even though they are considered important, are still rarely discussed in the English language teaching studies. Thus, comprehensive study on how ethical dilemmas in English teaching research need to be explained in depth. ELT researchers need to have a clear configuration of ethical dimensions which is very important to serve them as a guidance in carrying out their research.

\section{ETHICAL DILEMMAS IN RESEARCH}

Frankfort-Nachmias and Nachmias (1992) mention that the primary ethical dilemma in research is to balance benefits and costs. Benefits are the results of scientific findings that contribute to the development of science through which human living conditions are improved. Risk or cost means the damaging impact/loss caused by research such as dignity, shame, loss of trust in social relationships, loss of autonomy and self-determination, and low self-esteem to physical losses such as disability, physical damage. Ethical dilemmas in research are not always 
black and white, ethical or unethical; instead, they move along a continuum (Brigham, 1998; Kamuya, et al., 2013).

Robson (2002) suggests ten questionable practices in social studies, such as involving people without their knowledge or consent, forcing them to participate in research, withholding information about the true nature of the research, deceiving participants in other ways, persuading them to take actions that reduce their self-esteem, violating the right to selfdetermination (e.g., seeking promote personal change promotion), exposing participants to physical or mental stress; invade their privacy, reducing participants' right to benefit from research actions, and disrespecting participants.

\section{Involving other people as research subjects without getting their permission}

Involving other people without their knowledge or permission in research is one form of unethical action. Joining research is voluntary, and thus making them research subjects for the benefit of researchers is a form of limiting their autonomy to make their own decisions (PadillaWalker et al., 2005; Marshall, et al., 2006). Learning from the author's experience as a reviewer, many writers fail to include this critical ethical issue in their methods. Many consider informed consent as a trivial issue. It is not uncommon for many writers to not provide sufficient privacy for their research subjects by writing their identities openly. What would we imagine if this researcher publishes sensitive issues such as bullying, sexuality, etc., and mentions the research subject's identity and the scene publicly? Of course, the research subjects felt embarrassed. This issue becomes a public disgrace to them. As a result, their reputation will be tarnished in the eyes of the public.

Some data are even classified as privacy. Privacy can be understood in three ways (Diener \& Crandall, 1978): the sensitivity of the information provided, the setting of the empirical research, and the dissemination of information on research data. Information sensitivity is how private information has the potential to threaten the privacy of the research subject (Cowles, 1988; Kraut, et al., 2004). Following are examples of sensitive information, such as religious choice, sexual orientation, income, racial prejudice, and other personal attributes such as intelligence, honesty, and courage are more sensitive items (APA, 2016). The place or setting/location of the research can vary from very private places to public places. Home, for example, is considered one of the most private places (Birchley, et al., 2017). Thus, making observations at home without the owner's consent is a violation of the law. When this private information is widely published through the media without consent, privacy rights are violated.

Second, the act of using data to publish without approval can be categorized as betrayal (Pendlebury \& Enslin, 2001). Moreover, the term 'treason' is usually applied to occasions where confidentially disclosed data is publicly disclosed in such a way as to cause embarrassment, anxiety, or possibly suffering to the subject or participant who discloses the information. This act can also be regarded as breaching the trust.

\section{Coercing other people to get involved in research}

The meaning of coercing is an attempt to convince people (people who do not want to) to do something by using force or threats. Under normal circumstances, generally, no one wants to 
do something "unclear," let alone accompanied by threats or coercion. Even if we do not realize it, we often want to do it too. Coercing people to participate in research indicates that there is pressure/coercion on others to obey the researchers' will.

Coercing can occur in its subtle form. Leak (1981) and (Keith-Spiege et al., 1993) have interesting findings of students' views of their lecturers' invitations to become research subjects. From the results of their study, it was found that most of the students considered the lecturer's invitation to be involved in research as a subtle coercing act. These students admitted that they were in difficult situations to refuse their lecturer's request, let alone involvement in this research as a condition for graduating from the course.

How about persuading others instead of coercing? Can the act of persuading, for example, by granting the prospective research subjects with gifts, be considered unethical? In America, this issue has become a matter of debate among the members of IRB (Tishler \& Bartholomae, 2002; Chang \& Mills, 2013). They concluded that everything related to financial compensation or financial remuneration caused by planned research activities such as travel costs and lodging rentals should fall within the limits of undue influence (Singer, 2008; Largent, et al., 2013; Largent \& Lynch, 2017). Undue influence means excessive persuasion that causes another person to act or refrain from acting by overcoming that person's free will and results in inequity. In short, any compensation should not be the main factor that encourages or influences the decision to participate in the research, such as participating in research to gain financial benefits.

Table 1. Percentages of Agreement on Coercion Items from Leak's study (1981)

\begin{tabular}{|c|c|c|c|}
\hline Item & Yes & Nuetral & No \\
\hline $\begin{array}{l}\text { Do you object to being recruited in cass for } \\
\text { participation? }\end{array}$ & $1 \%$ & $3 \%$ & $96 \%$ \\
\hline Did you feel coerced or forced into participating? & $2 \%$ & $1 \%$ & $97 \%$ \\
\hline $\begin{array}{l}\text { Is the giving of extra credit for participating coercive to } \\
\text { you? }\end{array}$ & $47 \%$ & $14 \%$ & $39 \%$ \\
\hline $\begin{array}{l}\text { Do you object to being given extra credit for } \\
\text { participation? }\end{array}$ & $3 \%$ & $1 \%$ & $96 \%$ \\
\hline $\begin{array}{l}\text { Is a professor encouraging students to volunteer to } \\
\text { participate in their research projects as subjects } \\
\text { unethical? }\end{array}$ & $34.8 \%$ & $1.7 \%$ & $63.5 \%$ \\
\hline $\begin{array}{l}\text { Is having a student be research a participant as part of a } \\
\text { course requirement (with no alternative) unethical? }\end{array}$ & $71.4 \%$ & $1.5 \%$ & $27.2 \%$ \\
\hline
\end{tabular}

\section{Deceiving people}

Deceiving or fraud means providing wrong information (direct) and a deliberate act not to disclose important information in research to subjects (indirect). Deceiving or omitting some of that information is not justifiable, let alone its impact on other people (Barrera \& Simpson, 2012; Alberti \& Güth, 2013). In the context of cheating, we need to distinguish between intentional deception to cheat and cheating as a method. The purpose of cheating to commit fraud is like the practice of counterfeiting, fabrication, and plagiarism.

Falsification includes manipulating research materials, equipment, or processes or changing or omitting/suppressing data or results without scientific or statistical justification 
(Johnson et al., 2001). The research is not accurately represented in the research record. The examples of falsification include having alteration of data to render a modification of the variances in the data, falsifying dates and experimental procedures in the study notebook, misrepresenting results from statistical analysis, misrepresenting the methods of an experiment misrepresenting the materials or methods of a research study in a published paper, providing false statements about the extent of a research study, and falsifying telephone call attempts to collect data for a survey study.

Fabrication is to make up data or results and record or report them. Examples of fabrication include completing a questionnaire for a fictitious subject, creating a makeup data set for an experiment, and inserting a clinical note into the research record to indicate compliance with an element of the protocol (Devine, et al., 2013).

Plagiarism is the copying of other people's work, such as ideas, designs, images, plans, code, and one's own previously written work, without adequate source references either in an identical or slightly adjusted fashion (Masic, 2014). A special case of plagiarism is "selfplagiarism" in which an author will use segments of his/her own published material in a new publication without reference

Deception can be justified as a research method if researchers can provide scientific justification for why they use this method (Miller et al., 2005; Marzano, 2007). In the fields of social science and psychology, this method is commonly used. The following is an acceptable deceiving procedure carried out by researchers. The researcher asked the research subjects to do the test. After the test was completed, the researcher falsely informed that the test results of the research subjects were declared all wrong. Researchers examined the impact of stress on students' motivation or seriousness in completing the test. Another example is the researcher providing incomplete information. Researchers asked students to take the test in a room around a noisy building repair area. The researchers did not inform the research subjects about the effects of noise as part of their research.

The following is an ethical guidance about deception method issued by the American Psychology Association (APA, 2016).

First, research should not be carried out if the deception method is not scientifically justified and does not provide significant prospects for scientific truth. For example, researchers use non-scientific approaches such as intuitive in finding answers to scientific research.

Second, research should not be conducted if it is expected to cause severe physical pain or emotional distress. For example, after receiving the test results done by a student, the teacher as a researcher said that the answers on the test were "not enough to make the students pass," and therefore, they had to repeat. If the impact of the researchers' lies/deception makes students stressed for a long time to hysteria, then this method cannot be carried out for those who experience severe stress. There are two ways that researchers must run when this fraud method is carried out: debriefing and dehoaxing methods (Sommers \& Miller, 2013).

In the debriefing method, the researcher provides accurate information about the study (nature, results, and conclusions) immediately after data collection is obtained (Sharpe \& Faye, 2009). This method is done to correct any misunderstandings that participants may have. Participants should be given a clear and informative explanation of the research design and methods used, and they should have the opportunity to ask questions. 
Second, the dehoaxing method is a method in which the researcher is obliged to convince the subjects that they have been deceived (Perry, 2013). The purpose of dehoaxing is to prevent possible future harm to the subject (their self-esteem can be threatened).

\section{IMPLICATIONS}

An ethical attitude is an attitude that researchers must have at every stage of research for the good of themselves, other people, institutions, and other parties affected by the results of their research. This issue brings some implications that researchers must pay attention to. In so doing, they protect themselves from any potential ethical violations that can potentially harm themselves or others if they are neglected.

\section{Informing research activities to respondents (informed consent)}

Informing the research plan and all matters related to the research subject is called informed consent (Dunn \& Jeste, 2001; Flory \& Emanuel, 2004). Researchers needs to inform the points of their research from the outset to obtain approval. Informed consent requires that research subjects have the right to be informed of all matters related to research and subsequently have the right to make their choice (intention) towards research. In short, informed consent is the procedure by which individuals choose whether to participate in an investigation after being informed of facts that may influence their decision. At this stage, researchers must provide complete information about all possible consequences and dangers. The researcher must provide complete information about all possible consequences and hazards (Frankfort-Nachmias \& Nachmias, 1992).

Four conditions must be met by prospective research subjects when we want to notify the research plan (Frankfort-Nachmias \& Nachmias, 1992). They must have four things. For example, prospective research subjects are competent, meaning they understand the information given by researchers. They also know that research is voluntary and have access to all information regarding research. At last, prospective research subjects understand the information of the research.

Competence implies that responsible and mature individuals will make the right decisions if provided with relevant information (Manti \& Licari, 2018). Researchers must ensure they do not involve individuals who cannot make such decisions because of immaturity or some form of psychological disorder.

Volunteering applies the principle of informed consent, thereby ensuring that participants are free to choose to participate (or not) in research and ensure that risk exposure is conscious and voluntary (Sankar, 2004). This element can be problematic, especially in medical research where unknowing patients are used as guinea pigs.

Complete information implies that consent is fully informed, although it is often impossible for the researcher to inform the subject of everything, e.g., statistical data treatment (Bhutta, 2004). In such circumstances, a reasonably informed consent strategy should be applied.

Understanding refers to the fact that participants fully understand the nature of a research project, even when the procedures are complex and involve risks (Manti \& Licari, 2018). Suggestions have been made to ensure that subjects fully understand the situation they are in, e.g., by using a highly educated subject, involving a consultant to explain difficulties, or 
incorporating into the research scheme the time lag between the request for participation and the time of decision making. If these four elements are present, the researcher can be sure that the subject's rights will be given due consideration.

The following are practical things that researchers can do in the early stages of research. Researchers must tell participants what they are doing, by whom, and for what purpose. Participants should know the identity of the researcher, the name of affiliation, if any. They also need to know whom to contact for information if they have a problem with the research process. This requirement includes contact information for researchers and university ethics board (IRB) contact information. Researchers must inform participants of any risks they may take by participating in the study. Researchers should inform participants what rights they have in the process, particularly the right to review the material and withdraw from the process. The researcher must indicate whether the participant's name will be used in the study, is there another name to be used, or is it a pseudonym? Researchers must indicate how research results will be disseminated and whether participants can expect to benefit in any way, financially or otherwise, from participating in the study (Decker et al., 2011). The researcher must demonstrate that participants are free to participate or not participate in the study without harming them. In the case of children, the consent must be signed by the legal guardian of the child (Edwards et al., 2012). Generally, this permission is given in writing.

\section{Getting permission for access and acceptance}

It is essential to respect the research place where the research will take place. This respect must be demonstrated by obtaining permission before entering a research field. This sensitivity to ethical behavior shows that we are researchers who are sensitive and respectful of our partners (Willinsky, 2006).

The first thing is that researchers must obtain permission from various parties who have authority over the place to be researched, such as school officials, teachers, students, and even parents or guardians of students. When meeting them, the researcher must be ready to provide all information related to his research. That information includes research objectives, overall schedule, practical benefits, design, methods and procedures, nature, sample or group, tests, data collection methods, research activities, research subjects to interview (Devers \& Frankel, 2000). Researchers must explain their observational needs, time involved in research, the expected level of disturbance, confidentiality concerning data, and the role of feedback. They must explain how findings can best be disseminated what assistance will be required within the organization and administration of the research.

\section{Promoting confidentiality}

The second way to protect participants' privacy rights is through a promise of confidentiality. This method requires a researcher to ensure the method guarantees their prospective participant privacy protection (Stiles \& Petrila, 2011; Ethicist, 2015). Some boundaries protect the confidentiality of information.

Overall, the more sensitive information is, the greater the protection will be. Researchers must ensure a guarantee of confidentiality, and if necessary, it is made in a letter of agreement. Kimmel (1988) notes that prospective respondents invited to be involved in research with 
sensitive topics are likely to refuse to cooperate when confidentiality guarantees are not made clear, not understood, or are likely to be violated. He concluded that the usefulness of the data in sensitive research areas might be strongly influenced by the inability of the researcher to deliver a credible promise of confidentiality.

Some techniques have been developed to allow public access to data and information without betraying confidentiality. Frankfort-Nachmias and Nachmias (1992) have suggested the removal of identifying information, such as removing names, addresses, or other means of identification from data released on individuals. They also suggest preparing rough report categories, such as releasing year of birth rather than the date of birth, mentioning profession but not specialization in that profession, general rather than specific information.

Frankfort-Nachmias and Nachmias (1992) underlined the need for confidentiality of participants' identities. These issues must be carried out with the consent of the participants. The essence of anonymity is that the information provided by participants should in no way reveal their identity. Therefore, a participant or subject is considered anonymous when the researcher or other person cannot identify the participant or subject from the information provided. Where this situation applies, participant privacy is guaranteed, no matter how personal or sensitive the information is. Thus, a respondent who fills out a questionnaire that has absolutely no identification - name, address, job details, or coded symbols - is ensured complete and total anonymity.

On the other hand, subjects who agreed to face-to-face interviews could not expect anonymity at all. At best, the interviewer can promise confidentiality. As such, the primary way to ensure anonymity is not to use participant names or other means of personal identification. Ways to achieve anonymity have been listed by Frankfort-Nachmias (1992), for example, the use of aliases and codes to identify people (to keep information about individuals separate from access to them) and the use of password protected files. This method may work satisfactorily in most situations. It is sometimes challenging to maintain guaranteed anonymity when, for example, combining data can uniquely identify individuals or institutions or when access exists (Walford, 2005). Names must be changed, places shifted, and fictional events added to prevent the subject's acquaintances from discovering their identity (Grinyer, 2002). Although one can go a long way down this road, there is no guarantee of total anonymity as far as the study of life is concerned. Research data may be transferred to a coded and unnamed datasheet (Kennedy, 2006). In addition, confidentiality can also be protected by obtaining a signed statement indicating the non-disclosure of the study, limiting access to data identifying the respondent, seeking the respondent's consent before any disclosure about the respondent is made (Kaiser, 2009).

\section{Being ethical in data analysis}

In terms of data analysis, educational researchers are warned to edit the data or fabricate the data. For example, researchers violate ethics when they claim that they have discovered cause and effect, or even probable cause and effect when their results show only a pattern of relationships. Failure to analyze and report effect sizes other than testing the significance of the null hypothesis can also be considered unethical, as these guidelines have been clearly defined in the APA manual (APA, 2016). Furthermore, the unusual amount of measurement error (sample 
results differ from population estimates) may cast doubt on the use of analysis in procedures such as factor analysis.

In reporting and presenting data, several additional ethical issues relate to correlational research. Educational researchers must not plagiarize other people's words, fail to report contradictory findings, publish the same evidence repeatedly, and omit negative findings and alternative explanations. On a broader level, a good scholarship work ethic indicates a willingness to share data with others, publish one's work in scientific journals and not leave research reports unused in the office drawer, and includes vital philosophical assumptions about research in writing. In a meta-analysis, Brown and Hedges (2009) point out the ethical concerns of researchers who fail to suitably abstract and analyze various studies' findings and how this can lead to erroneous results. They were also concerned about the varying quality of correlational studies used in the meta-analyses and how unethical it would be for researchers to exclude studies due to small sample sizes and insignificant results.

\section{Appreciating participants}

There is a possible failure of researchers to feel indebted to their subjects for their services (Sinclair, 2017). This omission could be avoided if the researcher was willing to spend a few minutes with the subjects afterward to thank them for their participation, answer their questions, assure them they did well, and generally talk to them for a while. Suppose the research involves the subject experiencing failure, feelings of isolation, or loss of self-esteem. In that case, the researcher must ensure that the study does not leave the research subject humiliated, insecure, and isolated compared to before the research was conducted.

From the subject's point of view, research procedures that are potentially degrading, an injury to self-esteem require caution if the researcher chooses to continue with the method (Longworth et al., 2018). There is reason to believe that at least some of the compliant subjects, coming from experiences with lower self-esteem, had to live with the realization that they were willing to give in destructiveness. Researchers need to reflect an attitude of compassion, respect, gratitude, and common sense without being too overbearing. Attention to the subject at the reporting stage also needs to be considered. Whatever the form of the written report, be it a report, article, chapter, or thesis, and no matter the intended audience, the author must acknowledge and thank all those who assisted in the research, even to the extent of identifying by name those whose contributions were significant. This act can be done in a preface, introduction, or footnote. All of this is a matter of common-sense ethics.

\section{Writing research reports ethically}

Writing research reports ethically needs to be done by researchers. Avoid using language that contains an interpretation bias (Lozano, 2014). This means that we need to use specific terms for persons that are accurate, clear, and free of bias. For example, we are better off writing ages 63-70 than over 62. Another example is to avoid writing man and woman when describing the gender of the research subject. Instead, we wrote men and women which means we involve more than one person in our research.

We also must be careful with labeling certain groups. This means calling people names they prefer and acknowledging that preferences for names change over time. For example, we 
should avoid writing words like the gays, schizophrenics or man and wife. On the other hand, writing gay men or people diagnosed with schizophrenia or husband and wife has a better connotation.

In writing a research report we also need to make sure that our writing has explanations that connote non stereotypical and unbiased adjectives. For example, it is better for us to write doctor or nonaggressive participants than woman doctor or nonaggressive women. Also, we must pay attention to people's statements rather than their disability. For example, we should write person with mental illness rather than mentally ill person.

\section{CONCLUSIONS}

Researchers from any field of disciplines, including those whose passion is in English teaching skills are always challenged to contribute their research findings to the development of science. Ethical considerations need to be adhered to when researchers involve humans as participants in their research. Researchers must adhere to a guide for conduct based on concern for the worth of humans. Researchers must seek truth objectively. However, it is sometimes unavoidable for research to encounter potential risks/disadvantages to others. Therefore, it is highly recommended that researchers should calculate all potential risks in advance. It is very important for researchers to make a concrete evaluation of ethical dimensions as they occur in research.

\section{REFERENCES}

Alberti, F., \& Güth, W. (2013). Studying deception without deceiving participants: An experiment of deception experiments. Journal of Economic Behavior \& Organization, 93(1), 196-204.

Alsan, M., Wanamaker, M., \& Hardeman, R. R. (2020). The Tuskegee study of untreated syphilis: A case study in peripheral trauma with implications for health professionals . Journal of general internal medicine, 35(1), 322-325.

APA. (2016). Revision of ethical standard 3.04 of the" Ethical Principles of Psychologists and Code of Conduct"(2002, as amended 2010). The American Psychologist, 71(9), 900.

Barrera, D., \& Simpson, B. (2012). Much ado about deception: Consequences of deceiving research participants in the social sciences. Sociological Methods \& Research, 41(3), 383-413.

Bhutta, Z. A. (2004). Beyond informed consent. Bulletin of the World Health Organization, $82(1), 771-777$.

Birchley, G., Huxtable, R., Murtagh, M., Ter Meulen, R., Flach, P., \& Gooberman-Hill, R. (2017). Smart homes, private homes? An empirical study of technology researchers' perceptions of ethical issues in developing smart-home health technologies. BMC medical ethics, 18(1), 1-13. 
Brigham, L. (1998). Representing the lives of women with learning difficulties: Ethical dilemmas in the research process. British Journal of Learning Disabilities, 26(4), 146150 .

Brown, B. L. (2009). Use and misuse of quantitative methods: Data collection, calculation, and presentation. Handbook of social research ethics, 373-385.

Cassell, E. J. (2000). The principles of the Belmont report revisited: how have respect for persons, beneficence, and justice been applied to clinical medicine? Hastings center report, 30(4), 12-21.

Cephe, P. T., \& Keles, Y. (2015). An investigation of English language teachers and students' views on ethical principles towards students. Educational Research and Reviews, 10(7), 975-986.

Chang, C. D., \& Mills, J. C. (2013). Effects of a reward system on resident research productivity. . JAMA Otolaryngology-Head \& Neck Surgery, 139(12), 1285-1290.

Cowles, K. V. (1988). Issues in qualitative research on sensitive topics. Western Journal of Nursing Research, 10(2), 163-179.

Decker, S. E., Naugle, A. E., Carter-Visscher, R., Bell, K., \& Seifert, A. (2011 ). Ethical issues in research on sensitive topics: Participants' experiences of distress and benefit. Journal of Empirical Research on Human Research Ethics, 6(3), 55-64.

Devers, K. J., \& Frankel, R. M. (2000). Study design in qualitative research--2: Sampling and data collection strategies . Education for health, 13(2), 263.

Devine, E. G., Waters, M. E., Putnam, M., Surprise, C., O’Malley, K., Richambault, C., \& Ciraulo, D. A. (2013). Concealment and fabrication by experienced research subjects. Clinical Trials, 10(6), 935-948.

Diener, E., \& Crandall, R. (1978). Ethics in social and behavioral research. U Chicago Press.

Dreger, A. (2011). Darkness's descent on the American Anthropological Association. . Human Nature, 22(3), 225-246.

Dunn, L. B., \& Jeste, D. V. (2001). Enhancing informed consent for research and treatment. Neuropsychopharmacology, 24(6), 595-607.

Eaton, S. (2020). Ethical considerations for research conducted with human participants in languages other than English. British Educational Research Journal, 46(4), 848-858.

Edwards, T. L., Watkins, E. E., Lotfizadeh, A. D., \& Poling, A. (2012). Intervention research to benefit people with autism: How old are the participants? Research in Autism Spectrum Disorder, 6(3), 996-999. 
Ethicist, P. (2015). Simplifying the complexity of confidentiality in research. Journal of Empirical Research on Human Research Ethics, 10(1), 100-102.

Flory, J., \& Emanuel, E. (2004). Interventions to improve research participants' understanding in informed consent for research: a systematic review. . Jama, 292(13), 1593-1601.

Frankfort-Nachmias, C., \& Nachmias, D. (1992). Research methods in the social sciences. St. Martin's Press.

Friesen, P., Kearns, L., Redman, B., \& Caplan, A. L. (2017). Rethinking the Belmont report? The American Journal of Bioethics, 17(7), 15-21.

Grinyer, A. (2002). The anonymity of research participants: assumptions, ethics and practicalities. Social research update, 36(1), 4.

Gu, M., \& Lai, C. (2019). An ethical analysis of how ESL teachers construct their professional identities through the use of information technology in teaching. British Educational Research Journal,, 45(5), 918-937.

Johnson, T. P., Parker, V., \& Clements, C. (2001). Detection and prevention of data falsification in survey research. Survey Research, 32(3), 1-2.

Kaiser, K. (2009). Protecting respondent confidentiality in qualitative research. Qualitative health research, 19 (11), 1632-1641.

Kamuya, D. M., Theobald, S. J., Munywoki, P. K., Koech, D., Geissler, W. P., \& Molyneux, S. C. (2013). Evolving friendships and shifting ethical dilemmas: Fieldworkers' experiences in a short term community based study in Kenya. Developing world bioethic, 13(1), 1-9.

Keith-Spiegel, P. C., Tabachnick, B. G., \& Allen, M. (1993). Ethics in academia: Students' vies of professors' actions. Ethics \& behavior, 3(2), 149-162.

Kennedy, H. (2006 ). Beyond anonymity, or future directions for internet identity research. New media \& society, 8(6), 859-876.

Kimmel, A. (1988). Ethics and values in applied social research. Sage., 12(1).

Kraut, R., Olson, J., Banaji, M., Bruckman, A., Cohen, J., \& Couper, M. (2004). Psychological research online: report of board of scientific affairs' advisory group on the conduct of research on the internet. American psychologist, 59(2), 105.

Largent, E. A., \& Lynch, H. F. (2017). Paying research participants: the outsized influence of "undue influence". IRB,, 39(4), 1. 
Largent, E., Grady, C., Miller, F. G., \& Wertheimer, A. (2013 ). Misconceptions about coercion and undue influence: reflections on the views of IRB members. . Bioethics, 27(9), 500507.

Leak, G. K. (1981). Student perception of coercion and value from participation in psychological research. Teaching of Psychology, 8(3), 147-149.

Longworth, C., Deakins, J., Rose, D., \& Gracey, F. (2018). The nature of self-esteem and its relationship to anxiety and depression in adult acquired brain injury. . Neuropsychological rehabilitation, 28(7), 1078-1094.

Lozano, G. A. (2014). Ethics of using language editing services in an era of digital communication and heavily multi-authored papers. Science and Engineering Ethics, 20(2), 363-377.

Manti, S., \& Licari, A. (2018). How to obtain informed consent for research. Breathe, 14(2), $145-152$.

Marshall, P. A., Adebamowo, C. A., Adeyemo, A. A., Ogundiran, T. O., Vekich, M., Strenski, T., \& Rotimi, C. N. (2006). Voluntary participation and informed consent to international genetic research . American journal of public health, 96(11), 1989-1995.

Marzano, M. (2007). Informed consent, deception, and research freedom in qualitative research . Qualitative Inquiry, 13(3), 417-436.

Masic, I. (2014). Plagiarism in scientific research and publications and how to prevent it. . Materia socio-médica, 26(2), 141.

Merrell, J., \& Williams, A. (1995). Beneficence, respect for autonomy, and justice: principles in practice . Nurse Researcher, 3(1), 24-34.

Miller, F. G., Wendler, D., \& Swartzman, L. C. (2005). Deception in research on the placebo effect. PLoS medicine, 2(9), e262.

Padilla-Walker, L. M., Zamboanga, B. L., Thompson, R. A., \& S. L. (2005). Extra credit as incentive for voluntary research participation. . Teaching of Psychology, 32(3), 150-153.

Pendlebury, S., \& Enslin, P. (2001). Representation, identification and trust: Towards an ethics of educational research. Journal of Philosophy of Education, 35(3), 361-370.

Perry, G. (2013). Deception and illusion in Milgram's accounts of the obedience experiments. Theoretical \& Applied Ethics, 2(2), 79-92.

Robson, C. (2002). Real world research: A resource for social scientists and practitionerresearchers. . Wiley-Blackwell. 
Sankar, P. (2004). Communication and miscommunication in informed consent to research. . Medical anthropology quarterly, 18(4), 429-446.

Sharpe, D., \& Faye, C. (2009). A second look at debriefing practices: Madness in our method? . Ethics \& behavior, 19(5), 432-447.

Shavers, V. L., Lynch, C. F., \& Burmeister, L. F. (2000). Knowledge of the Tuskegee study and its impact on the willingness to participate in medical research studies. Journal of the National Medical Association, 92(12), 563.

Shuster, E. (1997). Fifty years later: the significance of the Nuremberg Code. New England Journal of Medicine, 337(20), 1436-1440.

Sims, J. M. (2010). A brief review of the Belmont report. Dimensions of critical care nursing, 29(4), 173-174.

Sinclair, C. (2017). Ethics in psychology: Recalling the past, acknowledging the present, and looking to the future. Canadian Psychology/psychologie canadienne, 58(1), 20.

Singer, E. \&. (2008 ). Do incentives exert undue influence on survey participation? Experimental evidence. Journal of empirical research on human research ethics, 3(3), 49-56.

Sommers, R., \& Miller, F. G. (2013). Forgoing debriefing in deceptive research: Is it ever ethical? Ethics \& Behavior, 23(2), 98-116.

Stiles, P. G., \& Petrila, J. (2011). Research and confidentiality: Legal issues and risk management strategies . Psychology, Public Policy, and Law, 17(3), 333.

Strike, K. A., Anderson, M. S., Curren, R., Van Geel, T., Pritchard, I., \& Robertson, E. (2002). Ethical standards of the American educational research association: Cases and commentary. American Educational Research Association.

Stufflebeam, D. L. (2004). A note on the purposes, development, and applicability of the Joint Committee Evaluation Standards. American Journal of Evaluation, 25(1), 99-102.

Tishler, C. L., \& Bartholomae, S. (2002 ). The recruitment of normal healthy volunteers: a review of the literature on the use of financial incentives. The Journal of Clinical Pharmacology, 42(4), 365-375.

Walford, G. (2005). Research ethical guidelines and anonymity. International Journal of research \& method in education, 28(1), 83-93.

White, R. M. (2000). Unraveling the Tuskegee study of untreated syphilis. Archives of Internal Medicine, 160(5), 585-598.

Willinsky, J. (2006). The access principle: The case for open access to research and scholarship. MIT Press. 